Rev Soc Esp Dolor

2014; 21(3): 186-187

\section{Una unidad del dolor multidisciplinaria en el ámbito de la sanidad privada}

\section{Sr. Director:}

John Bonica creó la primera unidad de tratamiento del dolor con el objetivo no sólo de tratar a los pacientes con dolor crónico, sino de estudiar y difundir el conocimiento del mismo. Siguiendo sus pasos, y como alumno suyo que fue, José Luis Madrid Arias introdujo la misma filosofía en nuestro país. Es de obligado cumplimiento pues que, todos aquellos que nos dedicamos a paliar el sufrimiento de los pacientes con dolor indistintamente en el ámbito público o privado, sigamos el camino trazado por ellos.

La Clínica del Dolor Praxis Bilbao es el resultado de un sueño hecho realidad. Nació en el año 2011 con el objetivo de tratar y mejorar la calidad de vida de los pacientes que sufren una de las peores lacras de la medicina como es el dolor crónico y la de difundir el conocimiento del mismo entre la sociedad y la clase médica en particular, con el convencimiento de que, a pesar del tiempo transcurrido y de las excelentes unidades del dolor repartidas por nuestro país, este sigue siendo el gran desconocido. El diagnóstico $\mathrm{y}$ tratamiento se realiza con un enfoque multidisciplinar, proporcionando a los pacientes una atención personalizada y exquisita en un ambiente adecuado y cuidado. Su actividad se desarrolla fundamentalmente en el ámbito estrictamente privado.

\section{Tratamientos para el dolor}

La clínica cuenta con los métodos terapéuticos más modernos e innovadores tanto farmacológicos como intervencionistas, siendo su mejor apuesta el abordaje multidisciplinar, atendiendo todas las esferas del dolor físicas y psíquicas. Los pacientes son evaluados por el equipo médico y en sesión clínica se programa el tratamiento más adecuado con la realización de protocolos según patología y haciendo un seguimiento periódico de la evolución y alta, si esta fuera posible.

Las técnicas intervencionsitas se realizan en el quirófano con la dotación necesaria para garantizar la eficacia y seguridad de las mismas: intensificador de imágenes, ecógrafo, monitorización básica, carro de anestesia y hospital de día.

\section{Equipo médico}

El equipo médico reúne las características que debe poseer el equipo de trabajo multidisciplinar: profesionales de especialidades diferentes, de edades distintas, predominando la gente joven y con un objetivo común: tratar a los pacientes con dolor crónico aportando una respuesta diferente a todo lo que anteriormente habían encontrado. Este trabajo multidisciplinar es imprescindible ya que el dolor, siempre orgánico, implica la suma del factor psicológico y el factor físico.

Su equipo lo conforman:

- 2 Especialistas en Anestesiología.

- 1 Especialista en Rehabilitación.

- 1 Especialista en Medicina Familiar.

- 1 Especialista en Psicología.

- 1 Fisioterapeuta.

- 1 Enfermera.

- 1 Técnico de Rayos.

- 1 Administrativa/Recepción.

Trabajando en equipo se identifican las bases del dolor y juntos se crea un programa único, adaptado a las necesidades del paciente y supervisado por expertos en todas las disciplinas.

\section{Labor divulgativa de la clínica}

Desde la experiencia acumulada con pacientes y la continua formación del personal se han extraído ideas, datos e información que ha sido ofrecida sin mayor interés que la propia evolución de este campo y así poder ofrecer un tratamiento más eficiente a toda aquella persona aquejada de dolor. De esta forma, los diferentes profesionales de la clínica han brindado charlas divulgativas sobre la prevención, recomendaciones y tratamiento del dolor crónico en diversas asociaciones, colegios y organizaciones.

Existe un convenio de colaboración con la UPV/EHU como centro seleccionado para las prácticas de alumnos de $3 .^{\circ}$ de medicina, y de trabajo conjunto con el departamento de fisiología.

\section{Conclusión}

El equipo de la Clínica del Dolor Praxis Bilbao comenzó su andadura con el ideal romántico de que el 
trabajo multidisciplinar sería el pilar fundamental sobre el que se asentaría la medicina del futuro, y probablemente así sea. Lamentablemente aún queda mucho trabajo para que esto sea posible y el mayor reto lo tenemos en nuestra propia casa, entre nuestros compañeros, muchos de los cuales desconocen completamente la función y labor de las unidades del dolor así como el procedimiento de derivación de pacientes. Además, se observa un trabajo por especialidades en vez de un trabajo entre especialidades en detrimento del tratamiento personal e individualizado.

Nuestra labor divulgativa se ha enfocado a insistir y convencer en el aspecto multidimensional del dolor, con el componente emocional siempre presente y la necesidad de un abordaje integral para su correcto tratamiento. Es en este campo donde más dificultades nos hemos encontrado con los pacientes y sobre todo con los profesionales sanitarios, que no acaban de comprender la importancia de la valoración conjunta con un especialista en psicología del paciente complejo con dolor crónico y ante la necesidad de realizar un tratamiento intervencionista. Con todo ello se ha notado nuestro esfuerzo porque ahora son ya los propios pacientes quienes demandan la asistencia multidisciplinar.
Hoy por hoy y en los tiempos que corren, y especialmente en nuestra comunidad, la del País Vasco, el ámbito privado de la sanidad no acaba de ser totalmente aceptado por la sociedad ya que, por suerte, disponemos de un sistema sanitario público excelente como es Osakidetza, y por ello queda mucho trabajo por hacer en lo que a concienciación se refiere. El grado de satisfacción entre pacientes y equipo médico es muy alto, y así se refleja en las encuestas de calidad; la pena es que no se refleje también en los datos económicos, siendo este factor el que más retrae al paciente privado.

La labor del equipo que compone esta clínica ha sido un reto y sobre todo un orgullo por el convencimiento que esta no es ni será inútil para la difusión del trabajo bien hecho en relación al abordaje multidisciplinar del dolor crónico, que aun viendo peligrar sus empleos han mantenido la forma y filosofía de trabajo inicial.

M. L. Franco

Servicio de Anestesiología y Tratamiento del Dolor. Clínica Dolor Praxis. Bilbao, Vizcaya 